\title{
Plant Species Richness Controls Arthropod Food Web: Evidence From an Experimental Model System
}

\author{
Zi-Hua Zhao, ${ }^{1,7, \oplus}$ Cang Hui, ${ }^{2,3}$ Gadi V. P. Reddy, ${ }^{4, \bullet}$ Fang Ouyang, ${ }^{5}$ Xing-Yuan Men, ${ }^{6}$ and \\ Feng $\mathrm{Ge}^{5}$
}

'Department of Entomology, College of Plant Protection, China Agricultural University, Beijing 100193, China, ${ }^{2}$ Centre for Invasion Biology, Department of Mathematical Sciences, Stellenbosch University, Matieland 7602, South Africa, ${ }^{3}$ Mathematical and Physical Biosciences, African Institute for Mathematical Sciences, Muizenberg 7945, South Africa, ${ }^{4}$ Montana State University, Department of Research Centers, Western Triangle Agricultural Research Center, Conrad, MT 59425, ${ }^{5}$ State Key Laboratory of Integrated Management of Pest Insects and Rodents, Institute of Zoology, Chinese Academy of Sciences, Beijing 100101, China, ${ }^{6}$ College of Plant Protection, Shandong Academy of Agricultural Sciences, Jinan 250100, China, and ${ }^{7}$ Corresponding author, e-mail: zhzhao@ cau.edu.cn

Subject Editor: Peijian Shi

Received 28 July 2018; Editorial decision 13 September 2018

\begin{abstract}
The effects of plant species richness on the function and stability of ecosystems have been an area of focus in recent decades. Arthropod community is one of the most important components in agroecosystems and can provide multiple ecosystem services, including biocontrol and pollination. In particular, species composition and biocontrol function can be sensitive to changes in plant species richness. Here, we designed 50 plots with five levels of plant species richness to examine arthropod distribution and composition over $4 \mathrm{yr}$. Arthropod richness was found to be positively correlated with plant species richness. High plant species richness can enhance the temporal stability of the arthropod community but can also lead to a decline in the population stability of some species. The species richness and biomass of environmentally friendly insects (EFI), such as honeybees, ants and flies, were found to be positively correlated with those of the natural enemies. As such, high levels of EFI could sustain food web robustness by serving as alternative prey/hosts for natural enemies. The mediation of EFI in the interaction between crops and pests has implications for successful biocontrol practices using natural enemies. Planting diverse plant species with a certain level of spatial turnover could benefit the biocontrol function of natural enemies and safeguard multiple ecosystem services.
\end{abstract}

Key words: biodiversity, diversity-stability hypothesis, food web, habitat management, natural enemy/pest ratio

Sustainable agricultural practices, aiming to reduce agrochemical inputs into regional atmosphere, water, and soil ecosystems, have been promoted worldwide (Tscharntke et al. 2012, Zhao et al. 2016). Many scientists have suggested the potential of increasing crop diversity, including genetic diversity, for achieving sustainable pest management (Haddad et al. 2011, Yang et al. 2014). To this end, the effects of plant diversity on the production and stability of agroecosystems have received substantial attention worldwide.

The diversity-stability hypothesis states that the stability of an ecosystem could be enhanced with the increase of plant diversity (Elton 1958). Studies in grasslands suggest that high plant richness can indeed increase the stability and production of the plant community (Hooper et al. 2005, Tylianakis et al. 2007). However, the relationship between plant richness and the function and stability of higher trophic level communities (e.g., arthropods) was still largely unknown (Hurd and Wolf 1974, Cardinale 2012). Most field experiments have only examined this relationship indirectly in natural ecosystems (Scherber et al. 2010). In a long-term experiment manipulating grassland plant species, high plant richness was found to enhance arthropod diversity and benefit pest management through improved temporal stability of food resources for natural enemies (Haddad et al. 2011).

The influence of plant diversity on the abundance and richness of natural enemies has been highlighted in our previous experiments (Zhao et al. 2013). However, how to enhance the activity of natural enemies and their biocontrol service by manipulating plant community remains largely unknown (van Veen et al. 2006, Tscharntke et al. 2012). Although some experiments have found that high plant species richness can enhance the abundance of natural enemies and their biocontrol of agricultural pests, other studies have not. Two hypotheses have been developed to interpret the effect of plant diversity on pest-natural enemy systems (Root 1973): the resource concentration 
hypothesis (in which herbivores are more likely to find and remain on hosts that are growing in dense or nearly pure stands) and the natural enemy hypothesis (in which diversified habitats promote the biocontrol service of herbivores through enhancing natural enemies). However, the effects of plant diversity on the function and stability of pest-natural enemy systems has rarely been studied.

Here, we designed five levels of plant richness to examine the relationship between plant species richness and arthropod communities using an experimental model system (EMS). Specifically, we asked three questions: 1 ) are the effects of plant species richness and biomass on species richness and biomass different across functional groups (i.e., between pests, natural enemies, and environmentally friendly insects [EFI]); 2) as per the diversity-stability hypothesis, will high plant species richness improve the temporal stability of the arthropod food web; and 3) how does the plant species richness affect biocontrol services? Answers to these questions would provide a theoretical basis for ecologically based pest management in agroecosystems.

\section{Materials and Methods}

\section{Experimental Design}

Our experimental area was located in Yishui County of Shandong Province, in northern China $\left(35^{\circ} 48^{\prime} 05^{\prime \prime} \mathrm{N}, 118^{\circ} 37^{\prime} 11^{\prime \prime} \mathrm{E}\right)$. The region is relatively flat (elevation from 101 to $916 \mathrm{~m}$ ) and has a temperate maritime, monsoon climate, with an annual sunshine accumulation of $2,421 \mathrm{~h}$, an annual mean temperature of $14.1^{\circ} \mathrm{C}$ and a frost-free period of $200 \mathrm{~d}$. The effective accumulated temperature $\left(>10^{\circ} \mathrm{C}\right)$ in the local agricultural fields is $2,390^{\circ} \mathrm{C}$. The mean annual precipitation is about $849 \mathrm{~mm}$, and the mean annual evaporation capacity is $1773.5 \mathrm{~mm}$. Irrigation is widely practiced in the regional agriculture, and grains are produced for several economic crops \{e.g., wheat (Triticum aestivum L. [Poales: Gramineae]), corn (Zea mays L. [Poales: Gramineae]), and soybean (Glycine max [L.] Merr. [Leguminales: Leguminosae])\}, which grow mainly in the regional Podzol E soil.

In this EMS from 2007 to 2010 (Zhao et al. 2013), we selected 20 primary crop plant species, including cotton (Gossypium spp.), corn (Zea mays L.), wheat (Triticum aestivum L.), soybean (Glycine max (L.) Merr.), tomato (Solanum lycopersicum L.), cabbage (Brassica oleracea L.), millet (Setaria italica (L.) Beauv.), sorghum (Sorghum bicolor (L.) Moench), ryegrass (Lolium perenne L.), red bean (Vigna angularis (Willd.) Ohwi et Ohashi), peanut (Arachis hypogaea L.), mung bean (Vigna radiata (L.) R. Wilczek), alfalfa (Medicago sativa L.), eggplant (Solanum melongena L.), celery (Apium graveolens L.), white clover (Trifolium repens L.), sunflower (Helianthus annuus L.), bean (Phaseolus vulgaris L.), rape (Brassica napus L.), and sesame (Sesamum indicum L.), all of which are grown in the province, and grew them at five different species richness levels (1, 2, 4, 8, and 16 crops) (Supp. Table S1). We designed fifty $9 \times 9 \mathrm{~m}$ plots that are $1 \mathrm{~m}$ apart (i.e., 1 $\mathrm{m}$ walking pathway), with 10 plots (replicates) for each richness level, covering an area of 1.05 ha $(70 \times 150 \mathrm{~m})$. For each plot, we randomly selected the appropriate number of species according to its richness level from the 20-species pool (so the same plant species richness in different plots could have different plant species compositions). Within each plot, plants were arranged in a matrix of 22 rows and 22 columns (484 plants). We kept the plant composition in each plot the same across the years. In each plot, the total number of plants (484) was apportioned across the number of species assigned to the plot $\left(S_{\mathrm{i}}\right)$.

Plant density and agricultural practices were kept the same in all plots. Herbicide was only applied to the walking pathway between plots before the growth of crops, to suppress weeds. No pesticides or chemical fertilizers, nor any other agrochemicals were applied to any plots. Farmland weeds were removed by hand during the growing period of crops.

We also designed a $5 \mathrm{~m}$ buffer belt surrounding the EMS. The buffer and EMS were surrounded by corn fields. A complete randomized block method was used to design the 50 plots. Such an experimental design can homogenize the background environment and largely eliminate stochastic variation among treatments. All plants were planted in early March of each year, with the level of plant species richness $(S)$ and plant arrangement kept the same year to year from 2007 to 2010 .

\section{Arthropod Sampling}

A cross-section sampling method was used to collect arthropods (Zhao et al. 2013). Specifically, we only collected samples from the central row of 22 plants in each plot, to minimize the potential spillover effect caused by arthropods in the surrounding habitats and adjacent plots. All arthropod species and their abundance on the 22 plants were counted and recorded by visual observation and hand collection. The arthropods were sampled five times each year, once a month from April to August. Species composition and the abundance for each functional group (pests, natural enemies, and EFI) were recorded with visual observation of all arthropods on the lower leaf surface. Both the top and bottom surfaces of the leaves was investigated the abundance of insects. A magnifying glass was used to look for small arthropods. Each plant was examined for $10 \mathrm{~min}$, for a total of $220 \mathrm{~min}$ per plot. The abundance of each arthropod species was transformed into individuals/22 plants for further analyses.

\section{Functional Groups of Arthropods}

Arthropods were classified into three functional groups according to their feeding characteristics and trophic positions: pests, natural enemies, and EFI. Pests (such as aphids, armyworm, and cotton bollworm) are phytophagous arthropods that can cause great damages to crops. Natural enemies (e.g., parasitic wasps, lady beetles, and lacewings) are parasitoids or predators. EFI (honeybee, ant, and flies) mainly feed on pollen and plant litter without directly causing damage to crops or feeding on pests. All collected arthropod species were identified into species level. All arthropod species were classified into these three functional groups for further analysis.

\section{Biomass Measurement}

To measure the biomass of the plants planted in plots, three individuals of each plant species at the end of the season, including both all below- and above-ground parts, were randomly collected and taken to the laboratory for measurement of whole plant dry biomass in each year during the 4-yr experiments.

For small arthropods (e.g., parasitic wasps), 100 individuals of each species were used to estimate the mean biomass of a single individual. For large arthropods (e.g., Coccinellidae), five individuals of each species were measured separately and then averaged.

The total dry organic matter of plants and arthropods (divided into pest, natural enemy, and EFI) was weighed after $72 \mathrm{~h}$ of drying at $60^{\circ} \mathrm{C}$ in an oven. The individual biomass of each arthropod species was first determined. The population biomass was the weighted sum of the component species times their abundance in each plot. The plant biomass was obtained by the same procedure.

\section{Statistical Analysis}

To examine the effects of plant species richness and biomass on arthropod community (species richness and biomass), we first 
summed the number of individuals for each arthropod species sampled five times within a year to eliminate the effects of sample date. We further conducted a detrending analysis to exclude the temporal trend across years (Tilman et al. 2006). We conducted a standardization process by computing the percentage of insect abundance of each plot in each year (from 2007 to 2010). This detrending analysis removed yearly dynamics of the insect community along with interference from other large-scale trends in environmental conditions such as temperature fluctuation.

After the above data-modification procedures, plant species richness and insect community (species richness and biomass) were designated as the fixed factor and response factor in the analysis, respectively, with a covariate of plant biomass and random factor of plot. Furthermore, arthropod biomass values, including for each functional group, were log-transformed to meet the assumption of normal distribution, which was a prerequisite for linear statistical analysis. After that, we used the partial correlation method to distinguish the contribution of plant species richness and biomass on the arthropod community (species richness and biomass of arthropod community including the three functional groups of pest, natural enemy, and EFI) by using pcor function in ggm package of $\mathrm{R}$ ( $\mathrm{R}$ Development Core Team 2015). Finally, a regression (exponential function) was computed to describe the relationship between plant species richness and insect community (number of species and biomass).

Effects of plant species richness on the stability of the arthropod community were also examined to explain community dynamics patterns on different plant species richness. We calculated the stability of the insect community in each year in each plot as $S=\mu / \sigma$, where $\mu$ and $\sigma$ are the mean and SD, respectively (Tilman et al. 2006). In fact, $\sigma / \mu$ was the coefficient of variation for the insect community (increasing $\sigma$ values mean an unstable community), which was the inverse of stability. For example, the mean and SD of insect species richness in each sampling period (five sampling dates from April to August) of $1 \mathrm{yr}$ could be computed to describe the patterns of insect species richness and stability. Generally, a high SD $(\sigma)$ of insect variables within a plot indicated high coefficients of variation and low stability of insect community. The stability of the three functional groups of pest, natural enemy, and EFI were calculated. Multivariate analysis of variance (MANOVA) was used to examine the relationship between the stability of the arthropod community (response variable) and plant species richness. Plant richness and plot were regarded as fixed and random effects, respectively. We found no correlation structure within plots, in that plot variable had no significant effects on the stability of insect species richness for all three functional groups. A nonlinear logarithmic function was used in the regression model to describe the relationship between plant species richness and the stability of arthropod richness.

The biomass for each functional group (pest, natural enemy, and EFI) was calculated, and the biomass ratio of natural enemy to pest (natural enemy/pest ratio) was used as an index of the biocontrol service (Zhao et al. 2013); the effect of plant richness on natural enemy/pest ratio was examined by analysis of variance (ANOVA). Species richness and natural enemy-pest ratio were independent and dependent variables, respectively. Plot was the random variable. In addition, we also examined the effects of the three functional groups (predators, parasitoids, and EFI) on the natural enemy/pest ratio by a backward stepwise procedure; for this analysis, the fixed factors with $P<0.05$ were left in the full model. Furthermore, the polynomial effects of natural enemy were tested by adding the fixed factors, (biomass) $^{2}$ and (species richness) ${ }^{2}$ to the model. As neither of these factors had noticeable additional explanatory power, we considered the relationships between biomass and natural enemy/pest ratio to be linear. R 3.1.0 was used for conducting the statistical analysis (R Development Core Team 2015). Sigma Plot 12.5 was used for drawing the graphs.

\section{Results}

A total of 252 arthropod species including 75 predators, 22 parasitoids, 39 pests, and 16 EFI were identified during the 4-yr experiment (Supp. Table S2). Plant species richness had a significant effect on total arthropod richness, as depicted by an exponential function (Table 1, Fig. 1A). Linear regression showed that arthropod biomass significantly increased with increasing plant species richness $(F=1482.612, P<0.001$, Fig. 1B, Table 1$)$. In contrast, plant biomass had no significant effects on either arthropod species richness or biomass $(F=-0.0633, P<0.9497$, Table 1$)$.

Plant species richness was strongly correlated with the species richness of all three functional groups (pest, natural enemy, and EFI) (Fig. 1, Table 1). Plant species richness had no effects on the biomass of pests and EFI, while having a significant effect on the biomass of natural enemies in the agroecosystem (Table 1). In contrast, plant biomass had no effects on the biomass of arthropod, pest, and EFI, but did have significant effects on the biomass of natural enemy (Table 1).

The effect of plant species richness on the stability of pest richness was positive $\left(F_{5,195}=13.26, P=0.001\right.$, Fig. $\left.2 \mathrm{~A}\right)$; increasing plant species richness significantly enhanced the stability of pest richness. Similar effects were found for the effect of plant richness on the richness stability of natural enemies and EFI (Natural enemy: $F_{5,195}=5.92, P=0.001$; EFI: $F_{5,195}=3.19, P=0.014$, Fig. 2B). In contrast, the biomass stability of pest, natural enemy and EFI was not affected by plant species richness (pest: $F_{5,195}=0.34, P=0.54$,

Table 1. Effects of plant species richness and plant biomass on species richness and biomass of the arthropod community (Corr. means correlation coefficient)

\begin{tabular}{lccc}
\hline Variables & Corr. & $F$ & $P$ \\
\hline $\begin{array}{l}\text { Pest species richness } \\
\quad \text { Plant species richness }\end{array}$ & 0.5264 & 5.7089 & $<0.001$ \\
$\quad$ Plant biomass & 0.1701 & 1.5910 & 0.1153 \\
Natural enemy species richness & & & \\
$\quad$ Plant species richness & 0.5342 & 5.8255 & $<0.001$ \\
$\quad$ Plant biomass & 0.2195 & 2.075 & 0.0411 \\
Environmentally friendly & & & \\
$\quad$ insect species richness & & & \\
$\quad$ Plant species richness & 0.3333 & 3.2597 & 0.002 \\
$\quad$ Plant biomass & -0.0186 & -0.1714 & 0.8644 \\
Arthropod species richness & & & \\
$\quad$ Plant species richness & 0.6297 & 7.4733 & $<0.001$ \\
$\quad$ Plant biomass & 0.1929 & 1.8135 & 0.0734 \\
Pest biomass & & & \\
$\quad$ Plant species richness & -0.1626 & 1.5191 & 0.1324 \\
$\quad$ Plant biomass & -0.1701 & -1.6158 & 0.1098 \\
Natural enemy biomass & & & \\
$\quad$ Plant species richness & 0.2189 & 2.0684 & 0.0416 \\
$\quad$ Plant biomass & 0.0252 & -0.2325 & 0.8166 \\
Environmentally friendly & & & \\
$\quad$ insect biomass & & & \\
$\quad \begin{array}{l}\text { Plant species richness } \\
\text { Plant biomass }\end{array}$ & 0.2035 & 1.9159 & 0.0587 \\
Arthropod biomass & -0.0323 & -0.2983 & 0.7662 \\
$\quad$ Plant species richness & 0.9999 & 1482.612 & $<0.001$ \\
$\quad$ Plant biomass & -0.0068 & -0.0633 & 0.9497 \\
\hline
\end{tabular}



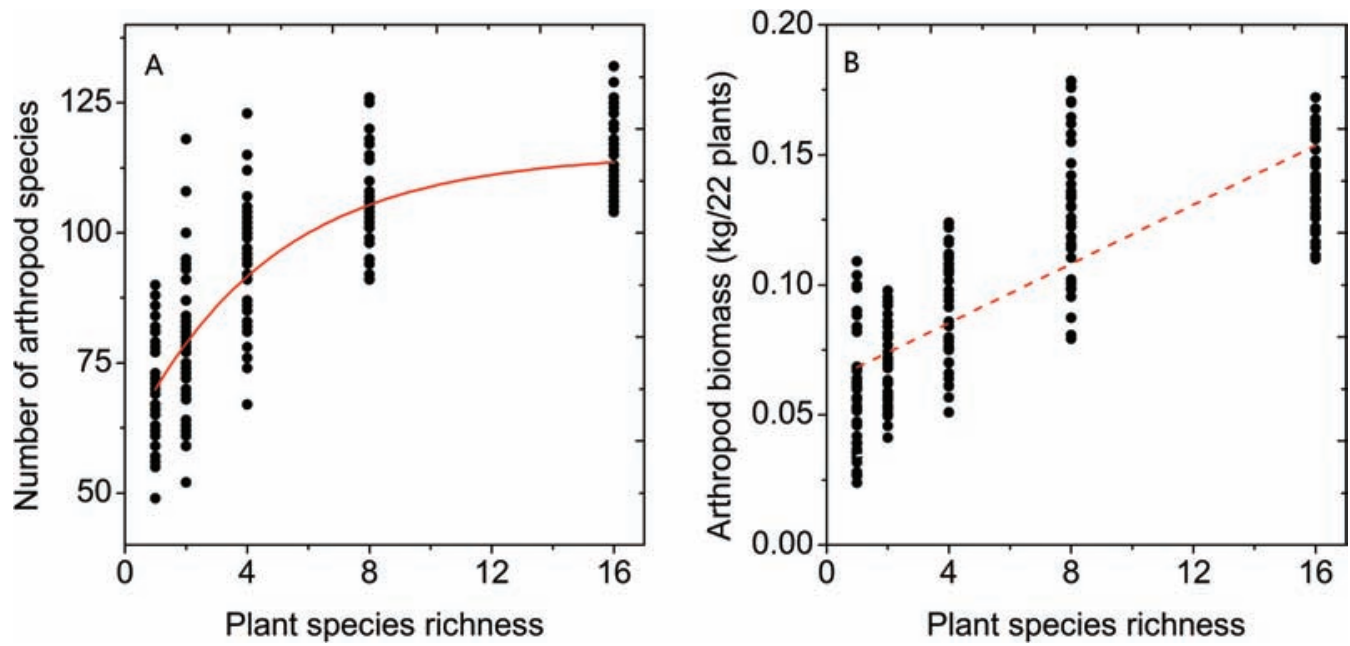

Fig. 1. The relationship between plant species richness and community of arthropod species (A, species number; $B$, biomass of arthropod).

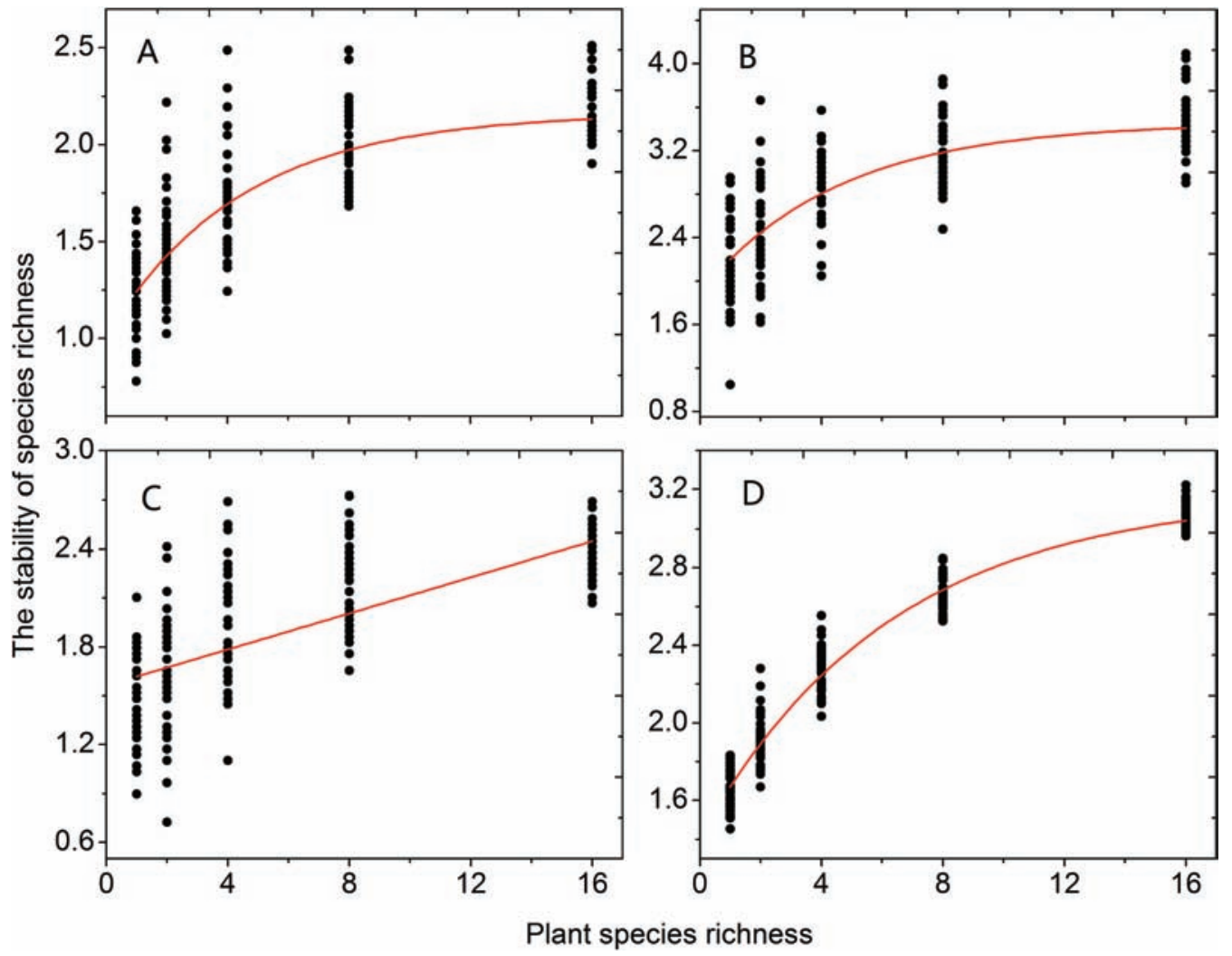

Fig. 2. The relationship between plant species richness and stability of species richness in arthropod community (A, pest; $B$, natural enemy; $C$, environmentally friendly insect; D, total arthropod community).

natural enemy: $F_{5,195}=0.23, P=0.76$, EFI: $F_{5,195}=0.54, P=0.38$, Fig. 2C and D).

We further examined the population stability of the dominant 15 species in each functional group (Supp. Table S3). The population stability of $7 / 15(46.7 \%)$ pest species was significantly affected by plant species richness; while for natural enemies, 11/15 species $(73.3 \%)$ were significantly affected and for EFL species, 10/14 $(71.4 \%)$ were affected (Supp. Table S3).

The natural enemy/pest ratio was generally low in plots with only one plant species and increased significantly with increasing plant species richness $\left(F_{5,195}=8.85, P=0.001\right.$, Fig. $\left.3 \mathrm{~A}\right)$. This ratio was also positively correlated with natural enemy biomass $\left(F_{5,195}=4.26\right.$, $P=0.002)$ and EFI biomass $\left(F_{5,195}=15.62, P=0.001\right.$, Fig. $\left.3 \mathrm{~B}\right)$, but negatively correlated with pest biomass $\left(F_{5,195}=3.65, P=0.007\right)$.

\section{Discussion}

Arthropod species richness and biomass were significantly enhanced by plant species richness, which is the most vital factor affecting plant biomass and arthropod community richness and stability 

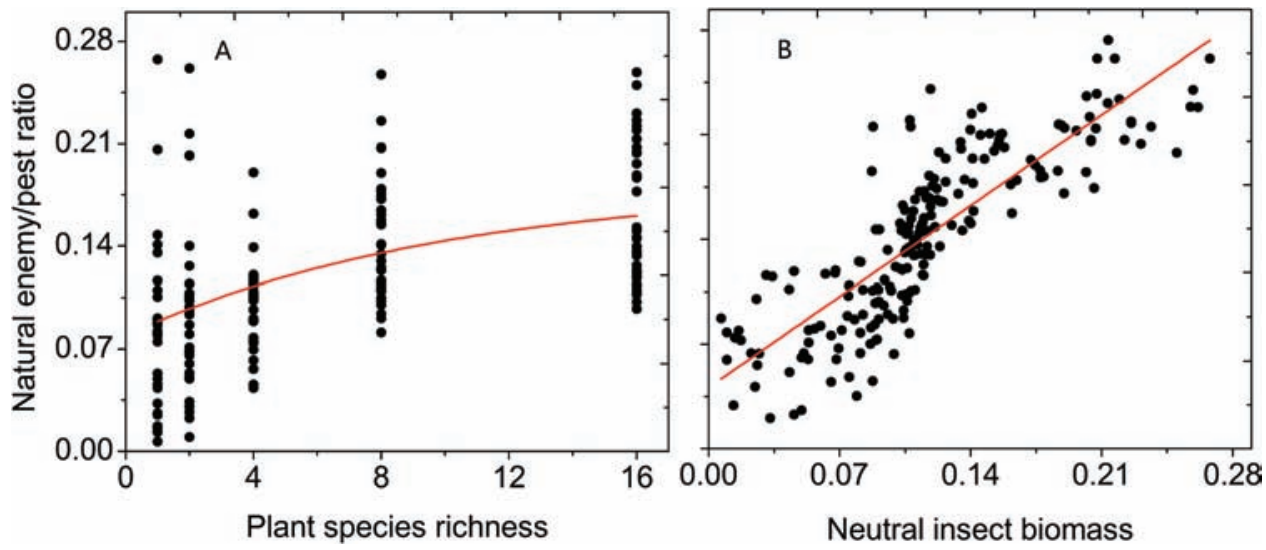

Fig. 3. The effects of plant species richness and environmentally friendly insect biomass on biocontrol service provided by natural enemy (A, relationship between plant species richness and natural enemy/pest ratios; $B$, relationship between environmentally friendly insect biomass and natural enemy/pest ratios).

(Morris et al. 2004, Tylianakis et al. 2007). Plant biomass can be strongly dependent on plant species richness, as demonstrated in several long-term experimental grassland studies, because diversified plant communities can more effectively absorb soil nutrition with efficient photosynthesis (Tilman et al. 1996, Tilman et al. 2001, Mueller et al. 2013). In addition, plant species richness can increase habitat heterogeneity and associated arthropod richness. Habitat heterogeneity, as reflected by high plant species richness, may be the most important mechanism mediating pest diversity (Montoya et al. 2003, Thies et al. 2011). In contrast, increasing plant biomass often leads to an increase in particular food resources, rather than increased diversity of food resources (Yang et al. 2012). As such, only certain species benefit from increasing plant biomass due to species-specific. Borer et al. (2012) have reported that the frequently observed correlation relationships between plants and arthropods occur primarily via changes in plant biomass, leading to changed arthropod biomass (Borer et al. 2012).

The positive correlation between plant species richness and the temporal stability of functional groups of arthropods indicates that the composition of the plant community could be used to predict ecological functions of the insect community (O'Gorman et al. 2009, Macfadyen et al. 2011, Yang et al. 2014), since a highly diversified plant community has more spatial-temporal niches and food resources, making interspecific relationships more complex and leading to a stable arthropod community (Borer et al. 2012). Higher plant species richness stabilizing the arthropod food web has also been observed in other long-term grassland experiments (Gross 2009, O'Gorman and Emmerson 2009, Haddad et al. 2011), with findings consistent with our results. However, the population stability of a particular species may not be enhanced by plant species richness at a population level. Higher plant species richness can provide multiple food resources and heterogeneous habitats, which may enhance intraspecific competition and thus fluctuation of arthropod species (Fabian et al. 2013, Isbell et al. 2013, Schneider et al. 2013).

The natural enemy/pest ratio also increase with increasing plant species richness, indicating a clear bottom-up effect (Macfadyen et al. 2011, Chaplin-Kramer et al. 2013). To our surprise, biomass of EFI had a strong positive correlation on the natural enemy/pest ratio in our study. However, EFIs rarely receive attention in the biocontrol of pests, even though they may play an important role in as alternative prey, sustaining natural enemy populations (ChaplinKramer et al. 2011, Veldtman et al. 2011). EFIs mainly provide a regulating service and promote a robust food web, and therefore they play an important role in maintaining ecological balance and sustaining ecological function (Brewer and Goodell 2012, Jonsson et al. 2012, Woltz et al. 2012). Furthermore, a low EFI biomass was disadvantageous to the natural enemy/pest ratio, demonstrating that EFIs may act as an alternative food and help maintain the robustness of the food chain when pest populations are absent in fields (Schneider et al. 2013).

Agroecosystems have experienced major planting pattern shifts caused by agricultural intensification, including decreasing plant diversity and cropland expansion, both of which drive a loss of biodiversity and reduction of biocontrol services in crop fields (Rand and Tscharntke 2007, Blanchet et al. 2013). Many other experiments have also adopted the EMS method (or microcosm model) to study the relationship of plant diversity, production, and stability in natural ecosystems (Scherber et al. 2010), but this method has only rarely been applied to agroecosystems. Accordingly, this EMS method provides a promising and useful tool for studying the mechanisms of plant-arthropod food web interactions in agricultural ecosystems (Tylianakis et al. 2007, Diehl et al. 2013).

Arthropods provide many ecosystems services, including pollination and biocontrol, and as such have an important effect on human activity (Thies et al. 2011, Poveda et al. 2012, Rand et al. 2012). Our results demonstrate that increasing plant species richness can maintain arthropod biodiversity, especially for natural enemies and EFIs, which in turn provide important ecosystem services. High plant species richness can also enhance the stability of the arthropod community and facilitate the biocontrol of pests by natural enemies via EFIs (Blanchet et al. 2013, Lohaus et al. 2013, Martin et al. 2013).

\section{Supplementary Data}

Supplementary data are available at Annals of the Entomological Society of America online.

\section{Acknowledgments}

We are grateful to Prof. Dahan He (College of Agriculture, Ningxia University) for statistical advice on the first draft of this manuscript. We would also like to thank students from the Shandong Agricultural University, Qingdao Agricultural University, and Hebei Agricultural University for experimental assistance and field collection. Financial support was partly provided by the National Key R \& D Program of China (2017YFD0200400) and the National Natural Science Foundations of China (31770453). 


\section{References Cited}

Blanchet, F. G., J. A. C. Bergeron, J. R. Spence, and F. L. He. 2013. Landscape effects of disturbance, habitat heterogeneity and spatial autocorrelation for a ground beetle (Carabidae) assemblage in mature boreal forest. Ecography. 36: 636-647.

Borer, E. T., E. W. Seabloom, D. Tilman, and V. Novotny. 2012. Plant diversity controls arthropod biomass and temporal stability. Ecol. Lett. 15: 1457-1464.

Brewer, M. J., and P. B. Goodell. 2012. Approaches and incentives to implement integrated pest management that addresses regional and environmental issues. Annu. Rev. Entomol. 57: 41-59.

Cardinale, B. J. 2012. Biodiversity loss and its impact on humanity. Nature. 489: 326 .

Chaplin-Kramer, R., M. E. O’Rourke, E. J. Blitzer, and C. Kremen. 2011. A meta-analysis of crop pest and natural enemy response to landscape complexity. Ecol. Lett. 14: 922-932.

Chaplin-Kramer, R., P. de Valpine, N. J. Mills, and C. Kremen. 2013. Detecting pest control services across spatial and temporal scales. Agr. Ecosyst. Environ. 181: 206-212.

Diehl, E., E. Sereda, V. Wolters, and K. Birkhofer. 2013. Effects of predator specialization, host plant and climate on biological control of aphids by natural enemies: a meta-analysis. J. Appl. Ecol. 50: 262-270.

Elton, C. S. 1958. The ecology of invasions by animals and plants. Methuen, London, United Kingdom.

Fabian, Y., N. Sandau, O. T. Bruggisser, A. Aebi, P. Kehrli, R. P. Rohr, R. E. Naisbit, and L. F. Bersier. 2013. The importance of landscape and spatial structure for hymenopteran-based food webs in an agro-ecosystem. J. Anim. Ecol. 82: 1203-1214.

Gross, T. 2009. Generalized models reveal stabilizing factors in food webs. Science. 325: 1341.

Haddad, N. M., G. M. Crutsinger, K. Gross, J. Haarstad, and D. Tilman. 2011. Plant diversity and the stability of foodwebs. Ecol. Lett. 14: 42-46.

Hooper, D. U., F. S. Chapin, J. J. Ewel, A. Hector, P. Inchausti, S. Lavorel, J. H. Lawton, D. M. Lodge, M. Loreau, S. Naeem, et al. 2005. Effects of biodiversity on ecosystem functioning: a consensus of current knowledge. Ecol. Monogr. 75: 3-35.

Hurd, L. E., and L. L. Wolf. 1974. Stability in relation to nutrient enrichment in arthropod consumers of old-field successional ecosystems. Ecol. Monogr. 44: 465-482.

Isbell, F., P. B. Reich, D. Tilman, S. E. Hobbie, S. Polasky, and S. Binder. 2013. Nutrient enrichment, biodiversity loss, and consequent declines in ecosystem productivity. Proc. Natl. Acad. Sci. USA 110: 11911-11916.

Jonsson, M., H. L. Buckley, B. S. Case, S. D. Wratten, R. J. Hale, and R. K. Didham. 2012. Agricultural intensification drives landscape-context effects on host-parasitoid interactions in agroecosystems. J. Appl. Ecol. 49: 706-714.

Lohaus, K., S. Vidal, and C. Thies. 2013. Farming practices change food web structures in cereal aphid-parasitoid-hyperparasitoid communities. Oecologia. 171: 249-259.

Macfadyen, S., R. H. Gibson, W. O. Symondson, and J. Memmott. 2011. Landscape structure influences modularity patterns in farm food webs: consequences for pest control. Ecol. Appl. 21: 516-524.

Martin, E. A., B. Reineking, B. Seo, and I. Steffan-Dewenter. 2013. Natural enemy interactions constrain pest control in complex agricultural landscapes. Proc. Natl. Acad. Sci. USA 110: 5534-5539.

Montoya, J. M., M. A. Rodriguez, and B. A. Hawkins. 2003. Food web complexity and higher-level ecosystem services. Ecol. Lett. 6: 587-593.

Morris, R. J., O. T. Lewis, and H. C. Godfray. 2004. Experimental evidence for apparent competition in a tropical forest food web. Nature. 428: 310-313.

Mueller, K. E., D. Tilman, D. A. Fornara, and S. E. Hobbie. 2013. Root depth distribution and the diversity-productivity relationship in a long-term grassland experiment. Ecology 94: 787-793.
O'Gorman, E. J., and M. C. Emmerson. 2009. Perturbations to trophic interactions and the stability of complex food webs. Proc. Natl. Acad. Sci. USA 106: 13393-13398.

Poveda, K., E. Martinez, M. F. Kersch-Becker, M. A. Bonilla, and T. Tscharntke. 2012. Landscape simplification and altitude affect biodiversity, herbivory and Andean potato yield. J. Appl. Ecol. 49: 513-522.

Rand, T. A., and T. Tscharntke. 2007. Contrasting effects of natural habitat loss on generalist and specialist aphid natural enemies. Oikos. 116: 1353-1362.

Rand, T. A., F. J. F. van Veen, and T. Tscharntke. 2012. Landscape complexity differentially benefits generalized fourth, over specialized third, trophic level natural enemies. Ecography. 35: 97-104.

R Development Core Team. 2015. R: a language and environment for statistical computing. R Foundation for Statistical Computing, Vienna, Austria.

Root, R. B. 1973. Organization of a plant-arthropod association in simple and diverse habitats - fauna of collards (Brassica-Oleracea). Ecol. Monogr. 43: 95-120.

Scherber, C., N. Eisenhauer, W. W. Weisser, B. Schmid, W. Voigt, M. Fischer, E. D. Schulze, C. Roscher, A. Weigelt, E. Allan, et al. 2010. Bottom-up effects of plant diversity on multitrophic interactions in a biodiversity experiment. Nature. 468: 553-556.

Schneider, G., J. Krauss, and I. Steffan-Dewenter. 2013. Predation rates on semi-natural grasslands depend on adjacent habitat type. Basic Appl. Ecol. 14: 614-621.

Thies, C., S. Haenke, C. Scherber, J. Bengtsson, R. Bommarco, L. W. Clement, P. Ceryngier, C. Dennis, M. Emmerson, V. Gagic, et al. 2011. The relationship between agricultural intensification and biological control: experimental tests across Europe. Ecol. Appl. 21: 2187-2196.

Tilman, D., D. Wedin, and J. Knops. 1996. Productivity and sustainability influenced by biodiversity in grassland ecosystems. Nature. 379: 718-720.

Tilman, D., P. B. Reich, J. Knops, D. Wedin, T. Mielke, and C. Lehman. 2001. Diversity and productivity in a long-term grassland experiment. Science. 294: 843-845.

Tilman, D., P. B. Reich, and J. M. Knops. 2006. Biodiversity and ecosystem stability in a decade-long grassland experiment. Nature. 441: 629-632.

Tscharntke, T., J. M. Tylianakis, T. A. Rand, R. K. Didham, L. Fahrig, P. Batáry, J. Bengtsson, Y. Clough, T. O. Crist, C. F. Dormann, et al. 2012. Landscape moderation of biodiversity patterns and processes - eight hypotheses. Biol. Rev. Camb. Philos. Soc. 87: 661-685.

Tylianakis, J. M., T. Tscharntke, and O. T. Lewis. 2007. Habitat modification alters the structure of tropical host-parasitoid food webs. Nature. 445: 202-205.

van Veen, F. J., R. J. Morris, and H. C. Godfray. 2006. Apparent competition, quantitative food webs, and the structure of phytophagous insect communities. Annu. Rev. Entomol. 51: 187-208.

Veldtman, R., T. F. Lado, A. Botes, S. Proches, A. E. Timm, H. Geertsema, and S. L. Chown. 2011. Creating novel food webs on introduced Australian acacias: indirect effects of galling biological control agents. Divers. Distrib. 17: 958-967.

Woltz, J. M., R. Isaacs, and D. A. Landis. 2012. Landscape structure and habitat management differentially influence insect natural enemies in an agricultural landscape. Agr. Ecosyst. Environ. 152: 40-49.

Yang, B., F. Ge, F. Ouyang, and M. Parajulee. 2012. Intra-species mixture alters pest and disease severity in cotton. Environ. Entomol. 41: 1029-1036.

Yang, B., M. Parajulee, F. Ouyang, G. Wu, and F. Ge. 2014. Intraspecies mixture exerted contrasting effects on nontarget arthropods of Bacillus thuringiensis cotton in northern China. Agr. Forest Entomol. 16: 24-32.

Zhao, Z. H., P. J. Shi, X. Y. Men, F. Ouyang, and F. Ge. 2013. Effects of crop species richness on pest-natural enemy systems based on an experimental model system using a microlandscape. Sci. China-Life Sci. 56: 758-766.

Zhao, Z. H., G. V. P. Reddy, C. Hui, and B. L. Li. 2016. Approaches and mechanisms for ecologically based pest management across multiple scales. Agr. Ecosyst. Environ. 230: 199-209. 